\title{
Teachers' Perception of the Role of Strategic Planning in Educational Development at Three Mission Secondary Boarding Schools in Manicaland Province
}

\author{
Oyedele, V. \\ Africa University, P.O. Box 1320, Mutare \\ oyedelev@africau.edu \\ Chikwature, W. \\ Mutare Polytechnic, Research Department \\ P.O. Box 640, Mutare \\ whatmorec@gmail.com
}

\begin{abstract}
The study looked at what the teachers make out of the role of strategic planning in educational development. This study was motivated by the significance of strategic planning and its role in giving a sense of purpose and direction capable of guiding implementers in making everyday choices about what actions should be taken in order to produce the expected results in education. The population for this study was made up of teachers in three United Methodist Secondary boarding schools, with two of the learning institutions in Mutasa district and one in Marange district, all in Manicaland education province. A qualitative research design was used to solicit the views of the respondents. The researchers adopted a qualitative perspective because he was more concerned about understanding individual perceptions, in this case, the teachers' perceptions of the role of strategic planning in educational development. The instruments used to collect data from the sample were observations, interviews and questionnaires. The findings from the study indicated that the teachers did not fully understand the concept of strategic planning and its role in educational development. The main recommendation given from the study was that organizations should acknowledge that their employees are their most valuable resource and therefore should make a commitment to provide their staff with continuous learning opportunities, especially on such key success factors as strategic planning and its role in educational development.
\end{abstract}

Keywords: role, strategic planning, educational development, mission secondary boarding school

\section{INTRODUCTION}

According to Kaufman and Herman (1991) strategic planning can be defined as a management tool for helping an organization to improve its performance by ensuring that its members are working towards the same goals and by continuously adjusting the direction of the organization to the changing environment. Oyedele and Chikwature (2016) further say that strategic planning is not just a cold technical undertaking that spells out future objectives to be reached and actions to be taken. Its role in educational development is to give a global sense of purpose and direction capable of guiding implementers in making everyday choices about what actions should be taken in order to produce the expected results.

Because of the seemingly lack of use of strategic planning as a tool for development, United Methodist Church mission secondary schools in Manicaland education province are no longer the outstanding schools that they used to be. Standards seem to have lowered and continue to seemingly plummet. For example, as the researchers observed at one of the High Schools, which is the biggest United Methodist Church mission secondary school, not only in Manicaland but in Zimbabwe, strategic planning seems to be of little significance and is not being covered in almost all areas of school activity. For example, strategic planning seems to lack in how the school is organized as a learning institution. The school seems not to be guided by shared vision and mission statements which link the school and the community co-values in order to build stakeholder consensus. The school is also failing to build stakeholder consensus by involving the stakeholders in activities such as the planning and developing the curriculum which can go a long way in building a sense of partnership, ownership and trust within the stakeholders. 
Another area of school activity not being covered by strategic planning at the institution is management systems and procedures. The teachers at the school do not seem to have a say in developing school's objectives, which has tended to become only the administration's occupation. These objectives are in turn not communicated effectively hence each employee does not seem to understand and is less committed to them.

Lack of strategic planning also is failing to guarantee the mobilization of requisite resources by the school. These are the required resources needed for the full functioning of the institution. The infrastructure has so much depreciated to the extent that very few classrooms have got doors and the furniture in the classrooms has become so strained due to over-enrollment to the extent that students have to hurry to the classrooms each and every day after the morning assembly to scramble for desks and chairs. This has led to curriculum planning is failing to meet the educational needs of students. Like in classes, the textbooks that are being made available are also not the most current and most comprehensible.

The lowering of standards in these educational institutions is not being addressed properly and this has prompted the researchers to take on this investigation. It is taken so lightly and quickly dismissed with generalized statements, with no one, especially the teachers, wanting to be associated with the depreciation of standards. Decision making that is grounded within the values and principles of strategic planning should be implemented always in these schools. According to Robbins (1991) strategic planning serves a variety of purposes in the development of organizations, including:

- Defining the purpose of the organization and to establish realistic goals and objectives.

- Communicating those goals and objectives to everyone within the organization.

- Developing a sense of ownership of the plan.

- Ensuring the most effective use is made of the organization's resources by focusing the resources on the key priorities.

- Listening to everyone's opinions in order to build consensus about where the organization is going.

One of the researchers had an opportunity to teach at a United Methodist Church mission secondary school within the Manicaland education province. Being a former student of that same school and having left the institution not so long ago, one of the researchers witnessed how this "big" school had depreciated only in a space of three years. For example, there was no clarity as to the purpose of the institution and the setting up of SMART goals and objectives, no communication of those goals and objectives to everyone within the school and no guarantee of the most effective use of the organization's resources by focusing the resources on the key priorities. There was now inadequate furniture in the classrooms averaging about 47 desks for 50-51 students per class and there were now holes on the classroom floors, walls and chalkboards, among other things. Having observed all this, the researchers decided to look at the teachers' perceptions of the role of strategic planning in three United Methodist Church mission secondary schools in Manicaland education province and how these perceptions might be affecting the schools.

The importance of strategic planning in educational development at a micro level and how the success of an educational institution can easily be affected by decision making that is not grounded within these values and principles prompted the researchers to take on this investigation since he could not have found a better starting point to launch an inquiry into the current mediocre status of United Methodist Church mission secondary schools in the Manicaland education province. In Zimbabwe, although other factors come into play at the macro level such as government education policies, the social, economic and political situations, at the micro level, an educator's knowledge and skills in vision-setting, planning, leading, managing and his/her values and attitudes towards empowering other education stakeholders and ensuring the success of the institution are pivotal. According to Sergiovanni et al (1980) strategic planning is of so much significance and is inevitably a precondition for success in any educational organization for it covers all areas of school activity such as curriculum planning, development and implementation, management systems and procedures, organization, mobilization of requisite resources and building stakeholder consensus. For example, strategic planning ensures that curriculum planners make sure that their curriculum planning meets the educational needs of students. Like in a Science class, it is the planners duty to make sure that the materials that are assembled are the most current and most comprehensible. When the scientists find something new, these discoveries should be included in the curriculum. Curriculum planning can be done in such a way as to accommodate many different learning styles. Depending on the subject being 
taught, lesson plans can implement ideas such as lectures, experiments, group work, field trips and research papers.

Bradford and Duncan (2000) explain that strategic planning also ensures that planners consider social forces coming from far and wide that can influence the organization like the ideas, cultures and values of various groups of people. Multicultural societies are very good examples of how the ideas and values of various groups can influence activities like curriculum planning. Curriculum planners need to make sure that the curriculum caters for all these various groups.

Strategic planning also brings awareness to curriculum planners about the importance of always considering external factors like current issues and trends in society which might necessitate the adjustment of certain elements of the curriculum. An example is the HIV/AIDS issue which has placed humanity at risk and has made it vital for young people to be educated about HIV/AIDS transmission before they are exposed to situations that may put them at the risk of being infected. Due to their capacity and universality, schools are targeted as settings for educating young people about such current trends and issues.

Strategic planning goes beyond curriculum planning to the training so that learning takes place, in other words, according to http://www.unesdoc.unesco.org/images/0018/001897/189757e.pdf, the curriculum is developed. The plans are made into official documents, as guides for teachers and are made obligatory. Teachers use curricula when trying to see what to teach to the students and when, to see what resources need to be made available and also when. According to www.ct.gov.com, an effective curriculum development process usually entails a structured needs assessment process to gather information and guide the curriculum development process. The above authority further suggests that the information commonly gathered through surveys, structured discussions and test data most frequently includes:

- Teacher analysis of the present curriculum to identify strengths, weaknesses, omissions and/or problems

- Sample lessons that illustrate curriculum implementation

- Sample assessments that illustrate the implementation of the curriculum

- Parent and other community members concerns and expectations for the program obtained through surveys and invitational meetings.

With this information teachers can revise and update their curriculum with new approaches to make the teaching and learning process more effective and enjoyable.

Another area of school activity covered by strategic planning is management systems and procedures. Heuser, B. (2010) suggest that the management should spell out who is to do what to in order to accomplish the organization's objectives. This information will indicate what each employee must do in order to help the department or work group meet its objectives. One approach is to list three to five major responsibilities of each position, then focus on these responsibilities. It is important that each employee knows and understands what is expected of him or her, therefore the management must communicate the objectives effectively. However employees are most likely to understand and be committed to objectives if they have a say in developing them.

Strategic planning also covers the concept of organization or how the school should be organized as a learning institution. Firstly, any learning institution guided by strategic planning should have a vision as well as a mission statement. A vision statement is an institution's long term plan, whilst a mission statement explains who does what, what will be done, when it will be done and why it is done. The rationale of these statements is to guide/clarify the steps to achieve the organization's vision as well as to motivate the stakeholders, among other things.

A well organized learning institution as entailed by strategic planning should also have some form of leadership, good premises, craft competent and literate personnel, a timetable, code of conduct for discipline, among other things.

Strategic planning also guarantees the mobilization of requisite resources by the teachers. These are the required resources needed for the full functioning of the institution. At a school these resources do not only include funds only but other things such as infrastructure, furniture, stationery, sporting facilities and equipment, personnel and even time itself.

Most importantly, strategic planning, in a school set up, can be utilized to build stakeholder consensus. This can be done firstly by the school building a shared vision which links the school and 
the community co-values. The school can also build stakeholder consensus by involving the stakeholders in planning and developing the curriculum. This will go a long way in building a sense of partnership, ownership and trust within the stakeholders. The stakeholders will then in return make sure they do the best they can not to see the school's plans fail. The school can also allow the community to use some of its facilities like the grounds as well as its infrastructure like the halls.

\section{Research Questions}

1. What is strategic planning?

2. How do the various teachers define strategic planning?

3. What do the teachers perceive as the role of strategic planning?

4. In what ways do the teachers believe they are applying the concept of strategic

5. Planning in their day to day work?

6. To what extent do the teachers believe that lack of strategic planning is affecting their work?

\section{MATERIALS AND MethodS}

\subsection{Research Design}

The researchers used the qualitative research design. The researchers adopted a qualitative perspective because he was more concerned about understanding individual perceptions, in this case, the teachers perceptions of the role of strategic planning in educational development at three selected U.M.C mission schools in Manicaland education province. The researchers doubted whether a scientific approach could have been used to quantify or reduce to numbers and statistics human perceptions and knowledge. The qualitative research design was the most appropriate design for the study since it was concerned with qualitative phenomena. The research design assisted the researchers in providing a clear and undistorted picture of the role of strategic planning in educational development through how it is perceived by teachers or as they understand and experience it. The research design being inductive in nature, the researchers managed to gather deep information and perceptions by establishing good rapport with the participants as he employed inductive qualitative data collection instruments like observation, semi-structured in-depth interviews, and questionnaires.

The research design not only used non-numerical and unstructured data but also typically had research questions and methods which were more general at the start and became focused as the study progressed, aimed at getting an in-depth understanding of the perception of teachers of the role of strategic planning in educational development and the extent to which it governs their work. The research design also assisted the researchers in utilizing smaller but focused samples than large random samples.

\subsection{Population}

The group of interest to the researchers or the group to whom the researchers generalized the information of the study was made up of teachers from three United Methodist Church mission schools in Manicaland education province, namely, Schools A, B and C, in Mutasa district and School $\mathrm{C}$ in Mutare district.

The researchers had to seek approval from the station chairpersons and school heads of each and every one of these mission centers first before including their teaching staff as part of the study's population.

\subsection{Sample and Sampling Procedures}

The researchers used the convenience sampling method as a method for selecting the three United Methodist Church mission secondary schools. With the use of this non-probability sampling technique, the stations were selected because of their convenient accessibility and proximity to the researchers.

The researchers also used the convenience sampling method as a method for selecting survey participants. Since qualitative research deals with smaller but focused samples, the researchers drew only ten participants per school, which resulted to a sample of thirty participants for the whole study. The participants were delineated mainly into two categories and this was according to their sex.

The researchers, in all cases, would make the most out of the times when the teachers were free, like during break-time when they would gather in the staff-room for tea and collect data from subjects that were accessible and also willing to participate in the survey. The subjects were selected just because they were the easiest to recruit for the study. It would have been ideal to test the entire population, but 
the population was just too large that it was impossible to include every individual. This is the reason why the researchers relied on convenience sampling.

\section{DAta Collection InSTRUMents}

\subsection{Observation}

The use of qualitative observational research method by the researchers actually began before the use of other methods of data collection. The researchers actually got some valuable contextual data upon entering the various institutions on foot. This involved the conscious use of the things the researchers saw, like how the infrastructure is sited and its state and even the discipline of the students he met along the way, which helped shape his understanding of situations and phenomena.

The next step the researchers took in implementing the qualitative observational method involved formulating a well-understood relationship between himself and the research participants. It was essential for the researchers to clarify to the research participants the role he was to play as an observer in order to ensure facilitation of the study and acceptance by the participants at the schools. In all cases the researchers played the role of a neutral observer. The researchers' role was to record the behaviors of the teachers as objectively as possible. This data collection method was mainly characterized by analysis of personal documents like scheme-cum-plans, produced by the teachers and direct observation. Since strategic planning is defined as a process of defining strategy, or direction, and making decisions on allocating resources to pursue this strategy for the future, the researchers wanted to confirm if the teachers were implementing strategic planning by planning for their future lessons in good time, that is, all the teachers should have been capable to produce scheme-cum-plans for the lessons they were going to teach. Direct observation included attending some of the lessons and its main strength was that as a neutral observer, the researchers had the opportunity to verify whether there were any discrepancies between what participants had said or documented and what actually did happen.

\subsection{Interview}

The researchers designed a semi structured interview schedule for interviewing the participants individually face-to-face. This interview schedule was designed with the intent of gaining insight into the experiences the researchers could not have elicited either through observation or through a questionnaire from the respondents. The researchers reassured the respondents that it was purely an academic study, guaranteed the respondents anonymity, and the interview method being less formal, promised to keep it as brief as possible so as not to interfere with their busy schedules.

The interview was administered directly by the researchers through a short list of open-ended questions. The questions being qualitative in nature, the researchers even encouraged the participants to expand upon their answers by providing additional contextual information. The semi-structured interview method being less formal proved to be a better way of catching the point of view of the teachers. The researchers could revise questions, if needed, during the process of data collection, leaving room for any additional questions to be asked. The semi-structured interview provided greater scope for discussion and learning about the opinions and views of the respondents. The open-ended questions mainly served to explore different facets of the issue.

\subsection{Questionnaire}

The researchers designed some questionnaires which he administered directly to the individual participants and were completed by the subjects themselves, upon receipt, within the research setting. The questions on the questionnaires mainly focused on the teachers' perceptions of the role of strategic planning in educational development. The researchers had to be there personally in order to verbally assure everyone who was willing to participate confidentiality, for there was fear among the teachers that the information would be disclosed for public consumption. The main instruction given by the researchers was for the participants not to write their names on the questionnaires. This instruction helped in guaranteeing the participants confidentiality of their responses, giving them more confidence to participate.

The questionnaires mainly comprised of open ended questions which served the purpose of collecting a range of possible responses. The interviewer-administered questionnaires had the advantage that unclear questions could be clarified to the respondent. Most importantly, the interviewer could also ensure that all the questions were answered by the intended subjects. 


\subsection{Data Analysis Procedure}

The first phase of data analysis was familiarization. The researchers had massive amounts of material from the data collection process and had to re-read the field notes made from the interviews and observations and re-read the questionnaires as well before formal analysis began.

The study also involved some degree of transcription. This was the process whereby the researchers had to convert handwritten field notes obtained from observations and interviews into one document for easy reading. With a transcript of everything that the researchers observed and recorded, he was able to get the whole picture of what happened and the chances of the analysis being biased were minimized.

After transcription, it was necessary to organize the data into sections that were easy to retrieve. For example, the researchers had to give each teacher a pseudonym. Names and other identifiable material had to be removed from the transcripts. The researchers had to keep this information that linked the pseudonym to the original informants confidential and destroyed this after the completion of the research.

The next phase that the researchers undertook was to code the data. The researchers had to examine the raw qualitative data in the transcripts and extract words, phrases, sentences or paragraphs and assign different labels or codes so that they can easily be retrieved for further comparison and analysis, and the identification of any patterns. The codes were mainly based on themes, topics, ideas and concepts found in the data.

Lastly, the researchers had to undergo the process or procedure whereby they moved from the qualitative data that had been collected into some form of explanation, understanding or interpretation of the people and situations he was investigating as Heuser (2010) directs. In other words, the researchers had to give meaning to the data collected. Since numbers are not used in qualitative data analysis, the researchers looked for categories or themes from the raw data to describe and explain phenomena.

\section{RESULT AND DISCUSSION}

\subsection{Observation Results}

Out of the 3 sampled United Methodist Church mission secondary boarding schools, which the researchers coded Schools A, B and C (which is the order in which the schools were sampled), he firstly observed that only 1 school, which was School C, had a well documented vision and mission statement that was easily accessible for the consumption of the teachers as well as the public. This revelation shows some contradiction between the teachers' interpretation of the role of strategic planning in educational development and the information on strategic planning, which, according to Kaufman and Herman (1991), recommends starting with the formulation of a mission statement and a vision statement.

Subsequently, the researchers continued to implement the qualitative observational method by checking personal documents like scheme-cum-plans, produced by the teachers. As Chikwature and Oyedele (2016) advocate the researchers had to verify if the teachers were putting into practice strategic planning by planning for their future lessons in good time since strategic planning is identified as a process of defining strategy, or direction, and making decisions on allocating resources to pursue this strategy for the future. All of the sampled 30 teachers within the 3 United Methodist Church mission secondary schools were capable of producing scheme-cum-plans for the lessons they were going to teach the whole term which confirmed that, in this case, the teachers correctly perceived the role of strategic planning in educational development by putting it into practice through planning for their future lessons in good time.

The researchers also consequently checked other documents like timetables and whether the teachers adhered to these timetables. All of the 30 teachers within the sample were able to produce timetables for their daily lessons, although 6 teachers $(2$ from School A, 3 from School B and 1 from School C, proved not to be punctual. The researchers noted this when they attended sample lessons that illustrated curriculum implementation. However, since all the teachers within the sample managed to produce timetables, which a significant number were also adhering to, at this point, it can be concluded that the teachers rightly identified the role of strategic planning in educational development by allocating time, as a resource, to pursue their strategies.

During these lessons the researchers, firstly, wanted to observe whether the teachers made sure that their lessons met the educational needs of the students, that is if the teachers made sure that the 
resources that were brought together, like textbooks, were the most comprehensible and were enough for every student. The researchers observed that out of the 3 schools he sampled, 2(Schools B and C) did not have enough textbooks for every student as most students were sharing at a ratio of 2-3 students per textbook. However, since strategic planning is key in making decisions on allocating resources to pursue strategies for the future, at this juncture, there is a huge discrepancy between the role strategic planning should have played in the development of education and how the teachers were taking it.

Secondly, during the lessons, the researchers wanted to observe whether curriculum implementation was done in such a way as to accommodate many different learning styles such as lectures, experiments, group work, field trips and research papers. The researchers observed that all the 30 participants mainly employed the lecture method whereby they simply dictated notes to the students, hence no participatory learning. Therefore, it can be concluded that the teachers did not perceive correctly the role strategic planning could have played in accommodating the different learning styles in order to make sure that their lessons met the educational needs of all students.

Thirdly, the researchers also verified if the teachers made sure that they considered the United Methodist Church culture and values as they implemented the curriculum, that is to provide quality education within a Christian context through which students can acquire knowledge and skills, grow in spiritual maturity, develop sound moral values and ethics. The researchers observed that all the 30 partakers mainly focused on the part of students acquiring the knowledge and the skills only as he observed nothing that resembled the church's culture and values in the lessons. This showed that the teachers lacked the insight which strategic planning is supposed to bring concerning how they should have been aware of the social forces like religion which should influence the curriculum.

Lastly, the researchers confirmed if the teachers also considered external factors like current issues and trends in society which might necessitate the adjustment of the manner in which they implement the curriculum, for example the HIV/AIDS issue. The researchers observed that the 30 participants did not use the platform of being teachers to also educate the students about current trends and issues which does not tally with the teaching of an educator who fully understands and appreciates the role of strategic planning in education.

\subsection{Interviews}

The interviews were administered directly by the researchers, face to face, to the individual participants through a semi structured interview schedule comprised of a short list of questions, most of them being open-ended because of the aspect of the research being qualitative in nature. The researchers made certain to the respondents that their names would not be publicly known and restored confidence in them that it was purely an academic study and in return, the interview schedule managed to elicit the experiences of the respondents. The fact of the interview method being less formal allowed the researchers to revise the questions if necessary without changing the main idea behind them. The first question was a closed question (Yes/No question) which asked the respondents whether they knew what strategic planning was. A majority of 23 participants ( 9 from school A, 5 from school B and 9 from school C) said they knew what strategic planning was whilst a minority of 7 (1 from school A, 5 from school B and 1 from school C) said they didn't.

The research being qualitative in nature, the researchers went on further to encourage the participants to elaborate their answers by explaining what they thought strategic planning was. Out of the 30 respondents, an insignificant number of 12 (5 from school A, 1 from school B and 6 from school C) managed to explain what strategic planning is, whilst 18 participants (5 from school A, 9 from school $\mathrm{B}$ and 4 from school C) failed to do so. This proves that although a majority of 23 participants ( 9 from school A, 5 from school B and 9 from school C) said they knew what strategic planning was from the previous closed question, they did not really understand the concept.

As a means of instigating greater discussion and learning about the opinions and views of the respondents, the researchers posed another open-ended question at the respondents and it mainly intended to get what the teachers perceive as the role of strategic planning in educational development. A minority of 13 out of 30 partakers of the study (7 from school A, 3 from school B and 3 from school C) correctly perceived the role of strategic planning in educational development whilst a significant number of 17 participants ( 3 from school A, 7 from school B and 7 from school C) wrongly identified the function of strategic planning in the development of education. This proves that 
in as much as the teachers could not define what strategic planning is, they did not understand its role in educational development either.

The forth question was another closed question which asked the teachers whether they did believe they were responding to critical issues in educational development by applying strategic planning in their day to day work. A significant number of 25 participants (10 from school A, 8 from school B and 7 from school C) said they were indeed reacting to important issues in educational development by applying strategic planning in their day to day work whilst a minority of 5 ( 0 from school A, 2 from school B and 3 from school C) said they weren't.

The researchers then asked the participants to follow up their response to the above question with an explanation concerning how they believed they were responding to critical issues in educational development by applying strategic planning in their day to day work. A minority of 11 participants (4 from school A, 3 from school B and 4 from school C) gave detailed explanations of how they were responding to important matters in educational development by relating strategic planning to their everyday work whilst a majority of 19 respondents (6 from school A, 7 from school B and 6 from school C) failed. This goes on to confirm that although a significant number of 25 participants from the previous question (10 from school A, 8 from school B and 7 from school C) claimed to have been reacting to important issues in educational development by applying strategic planning in their day to day work, only a minority of 11 participants really seemed have been doing so.

The sixth question was a closed question which asked the teachers whether they had clear visions of what they wanted to achieve as teachers. A majority of 26 participants (10 from school A, 7 from school B and 9 from school C) said they had clear visions of what they wanted to achieve as teachers whilst a minority of 4 ( 0 from school A, 3 from school B and 1 from school C) said they didn't.

Subsequently, as a means of catching the point of view of the teachers, the researchers asked the interviewees to clarify further what their visions were. An insignificant number of 11 participants (3 from school A, 5 from school B and 3 from school C) managed to give clear visions that had a future focus whilst a majority of 19 respondents ( 7 from school A, 5 from school B and 7 from school C) failed to further clarify the visions they had as teachers. This was mainly because most of the explanations they gave did not focus on the future. This therefore proves that although a majority of 26 participants (10 from school A, 7 from school B and 9 from school C) had allegedly claimed to have clear visions of what they wanted to achieve as teachers, it was only 11 participants who really seemed to have them.

\subsection{Questionnaires}

The researchers also made use of the questionnaire as a data collection instrument. These were handed to the individual partakers of the study, directly by the researchers. There was fear among most of the teachers at first that the information would be disclosed to the public but the main instruction given by the researchers for the participants not to write their names on the questionnaires assured every participant of the confidentiality they so much needed which gave them more self-assurance to take part. The questionnaires were filled in within the location of the research, by the subjects themselves, upon receiving them.

Question number one on the questionnaire read: Do you regularly reflect on the strengths, weaknesses, opportunities and threats (SWOT) in the internal and external environment? On this question, the respondents were expected to give a simple answer of either a yes or no. A majority of 21 participants from the sample (10 from school A, 5 from school B and 6 from school C) said yes whilst a minority of 9 participants ( 0 from school A, 5 from school B and 4 from school C said no.

The next question which was the second part of the first question, was an open-ended question in which the respondents were individually expected to provide a short explanation for the answer they gave for the question previously asked, that is if they happened to respond with a yes. The researchers resorted to an open-ended question because he did not want to limit the degree to which the responses came through and wanted the respondents to explain how they reflect on their SWOT. Out of the 21 respondents who said they did, only 9 respondents (4 from school A, 2 from school B and 3 from school C) managed to give details on how they reflect on their SWOT whilst 12 participants (6 from school A, 3 from school B and 3 from C) were unsuccessful in doing so. This therefore provided evidence that only an insignificant number of 9 respondents out of a potential 30 really did regularly reflect on the strengths, weaknesses, opportunities and threats (SWOT) in the internal and external environment. 
The third question on the questionnaire read: Do you have clear goals and objectives for what you want to achieve as an educator- SMART goals? On this question, the respondents were also expected to give a simple yes or no answer. A majority of 27 participants from the sample (10 from school A, 7 from school B and 10 from school C) said yes whilst a minority of 3 participants (0 from school A, 3 from school B and 0 from school C said they didn't have clear goals and objectives for what they wanted to achieve as teachers. So, presumably, a majority of 27 participants out of 30 from the sample had clear goals and objectives for what they wanted to achieve as an teachers.

The fourth question read: Do you have clear indicators by which you measure the impact of your work as a teacher? Yes/No. A majority of 27 participants from the sample (10 from school A, 7 from school B and 10 from school C) said they did have clear indicators by which they measured the impact of their work as teachers whilst a minority of 3 participants ( 0 from school A, 3 from school B and 0 from school $\mathrm{C}$ said they didn't.

The fifth question was a follow-up to question number four in which those participants who had responded with a yes were expected to justify, in brief, the clear indicators by which they measured the impact of their work as teachers. A minority of 10 respondents (4 from school A, 1 from school B and 5 from school C) out of 27 managed to justify the clear indicators by which they measured the impact of their work as teachers whilst a significant number of 17 (6 from school A, 6 from school B and 5 from school C) failed. Therefore it becomes apparent that the teachers were not fully aware of the indicators which they were supposed to employ to measure the impact of your work.

Question number six read: Is there an agreement between your strategic plans and the values of the school? A significant number of 29 participants from the sample (9 from school A, 10 from school B and 10 from school C) said there is an agreement between their strategic plans and the values of the school whilst a minority of 1 participant ( 1 from school A, 0 from school B and 0 from school C said there isn't. So, 29 participants from the sample supposedly had strategic plans which agreed with the values of the school.

Question number seven also required the partakers of this study to give a response of either a yes or a no and it went as follows: Do you ensure the most effective use of the organization's resources for educational development? A considerable number of 30 participants, that is every educator within the sample, said he/she ensured the most effective use of the organization's resources.

In question eight, those participants who had agreed that they ensure the most effective use of the organization's resources for educational development were asked to explain how they do this. A $100 \%$ majority (10 from school A, 10 from school B and 10 from school C) explained how they ensure the most effective use of the organization's resources for educational development. This shows that the teachers were making use of some of the school's resources although they failed to broaden the scope of the word 'resource' to refer to other things besides textbooks and the library only.

Question number nine required the participants to respond with either a yes or a no and it read: Do you communicate with other fellow teachers at your school in order to build consensus about where the organization should go? A significant number of 30 participants from the sample (10 from school a, 10 from school B and 10 from school C) said they do communicate with other fellow teachers at their respective schools in order to build consensus about where the organization should go. So, a $100 \%$ majority of 30 respondents allegedly communicated with other fellow teachers at their schools in order to build consensus about where the organization should go.

The tenth question, which was the last question on the questionnaire, was an open-ended one and it read: What information do you think is most important to share with other teachers about the role of the strategic planning process in educational development? A minority of 8 respondents (4 from school A, 1 from school B and 3 from school C) managed to give responses worth sharing with other teachers about the role of the strategic planning process in educational development whilst a significant number of 22 respondents could not. This goes on to illustrate the limited range of knowledge on strategic planning and its role in the process educational development that the teachers from the sample had.

\section{Conclusions}

From the researchers' findings it can be concluded that the teachers do not fully understand the concept of strategic planning and its role in educational development. This was revealed at multiple stages during the data presentation and analysis process although it was mainly proven at two key 
points during the interviews, the first one being when a majority of 23 participants which had allegedly claimed to know what strategic planning is from a previous closed question failed to define the concept on the next part of the question, which was an open-ended one.

Secondly, this was also exposed when the researchers posed another open-ended question at the respondents which intended to get what the teachers perceive as the role of strategic planning in educational development and a minority of 13 out of 30 respondents correctly perceived its role. This proved that in as much as the teachers could not define what strategic planning is, they did not understand its role in educational development either.

\section{RECOMMENDATIONS}

- Organizations should acknowledge that their employees are their most valuable resource and therefore should make a commitment to provide their staff with continuous learning opportunities, especially on such key success factors as strategic planning and its role in educational development. This is a strategy that makes sense. This can be done through staff development meetings or seminars whereby knowledgeable individuals on such issues are given the platform to share their knowledge. These can either be teachers at the school or even hired professionals.

- Schools can also provide funds for their teachers to go for strategic planning courses or can simply allow those staff members who want to fund their own education to freely do so, if the schools can't.

- Organizations should indeed recognize the importance of including training as a key element in their strategic planning process.

\section{REFERENCES}

Bradford and Duncan (2000). Simplified Strategic Planning. Tennessee. Chandler House.

Chikwature W. and Oyedele V. (2016). An Analysis of the Effects of Monetary and Non-Monetary Incentives on Performance Levels of Employees in Organisations: A Case of Mutare Polytechnic, January 2013 to December 2015. Greener Journal of Educational Research, 6(1):026-033,

Heuser, B. (2010) The Evolution of Strategy: Thinking War from Antiquity to the Present. Cambridge University Press.

http://www.ct.gov.com

http://www.unesdoc.unesco.org/images/0018/001897/189757e.pdf

Kaufman, R; Herman, J. (1991) Strategic Planning in Education: Rethinking, restructuring, revitalizing. Lancaster, PA: Technomic Publishing Company.

Oyedele, V. and Chikwature, W (2016) Evaluating the Strategic Management Skills Exhibitted by Government Secondary School Administrators In Mutare District: European Journal of Research and Reflection in Management Sciences, 4 (3), 1-23.

Sergiovanni, T.J, Butlingame, Coombs, F.A and Thurston, P.W. (1980) Educational Governance and Administration. New Jersey. Prentice-Hall Inc.

\section{AUTHORS' BIOGRAPHY}

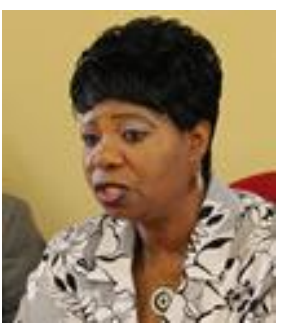

Dr. Oyedele Victoria, PhD and Master in Curriculum Studies, BSc. Ed (Biology). Senior lecturer and Dean of Students in the Faculty of Education at Africa University. Expert in Research Methods and Statistics, Curriculum Studies and Educational Evaluation. She has written over 20 research papers on educational leadership and administration. She has written some books also notably in Research Methods and Statistics and on Curriculum issues.

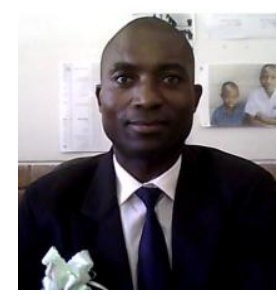

Dr. Chikwature Whatmore, He holds a $\mathrm{PhD}$ in Education, Master of Education in Educational Management, Bachelor of Arts in English and Communication Studies, Diploma in Secondary Education, and many other credentials and has started on his second $\mathrm{PhD}$ in Educational Administration. He is Research Methods and Statistics senior lecturer and Human Resource Development senior lecturer at Mutare Polytechnic. He is also a part time lecturer in Masters of Educational Leadership, and Management Programme at Africa University in these subjects: Research Methods and Statistics, Leadership, and Policy studies and Educational Administration. Published 19 research papers to date on Educational Leadership and Management issues. 